\title{
Women's overall satisfaction with health facility delivery services in Ghana: a mixed-methods study
}

Kwame K. Adjei ${ }^{1}$, Kimiyo Kikuchi ${ }^{2}$, Seth Owusu-Agyei ${ }^{1,3}$, Yeetey Enuameh ${ }^{1,4}$, Akira Shibanuma ${ }^{5}$, Evelyn Korkor Ansah ${ }^{3,11}$, Junko Yasuoka ${ }^{6}$, Kwaku Poku-Asante', Sumiyo Okawa ${ }^{5}$, Margaret Gyapong ${ }^{3}$, Charlotte Tawiah ${ }^{1}$, Abraham Rexford Oduro ${ }^{7}$, Evelyn Sakeah ${ }^{7}$, Doris Sarpong ${ }^{8}$, Keiko Nanishi', Gloria Quansah Asare ${ }^{10}$, Abraham Hodgson ${ }^{11}$, Masamine Jimba ${ }^{5^{*}}$ and Ghana EMBRACE Implementation Research Project Team

\begin{abstract}
Background: Skilled birth delivery has increased up to nearly $74 \%$ in Ghana, but its quality has been questioned over the years. As understanding women's satisfaction could be important to improving service quality, this study aimed to determine what factors were associated with women's overall satisfaction with delivery services quantitatively and qualitatively in rural Ghanaian health facilities.

Results: This cross-sectional, mixed methods study used an explanatory sequential design across three Ghana Health Service research areas in 2013. Participants were women who had delivered in the preceding 2 years. Two-stage random sampling was used to recruit women for the quantitative survey. Relationships between women's socio-demographic characteristics and their overall satisfaction with health facility delivery services were examined using univariate and multiple logistic regression analyses. For qualitative analyses, women who completed the quantitative survey were purposively selected to participate in focus group discussions. Data from the focus group discussions were analyzed based on predefined and emerging themes. Overall, 1130 women were included in the quantitative analyses and 136 women participated in 15 focus group discussions. Women's mean age was 29 years. Nearly all women (94\%) were satisfied with the overall services received during delivery. Women with middle level/junior high school education [adjusted odds ratio (AOR) $=0.50,95 \%$ confidence interval (Cl) $=(0.26-0.98)]$ were less likely to be satisfied with overall delivery services compared to women with no education. Qualitatively, women were not satisfied with the unconventional demands, negative attitude, and unavailability of healthcare workers, as well as the long wait time.

Conclusions: Although most women were satisfied with the overall service they received during delivery, they were not satisfied with specific aspects of the health services; therefore, higher quality service delivery is necessary to improve women's satisfaction. Additional sensitivity training and a reduction in work hours may also improve the experience of clients.
\end{abstract}

Keywords: Maternal health, Child health, Pregnancy, Client satisfaction, Ghana, Mixed methods

\footnotetext{
* Correspondence: mjimba@m.u-tokyo.ac.jp

${ }^{5}$ Department of Community and Global Health, Graduate School of

Medicine, The University of Tokyo, 7-3-1, Hongo, Bunkyo-ku, Tokyo 113-0033,

Japan

Full list of author information is available at the end of the article
}

(C) The Author(s). 2019 Open Access This article is distributed under the terms of the Creative Commons Attribution 4.0 International License (http://creativecommons.org/licenses/by/4.0/), which permits unrestricted use, distribution, and reproduction in any medium, provided you give appropriate credit to the original author(s) and the source, provide a link to the Creative Commons license, and indicate if changes were made. The Creative Commons Public Domain Dedication waiver (http://creativecommons.org/publicdomain/zero/1.0/) applies to the data made available in this article, unless otherwise stated. 


\section{Background}

The provision of delivery services by skilled health personnel is vital to improving maternal health [1]; however, between 2012 and 2017, about 50\% of deliveries in sub-Saharan Africa (SSA) were performed by skilled personnel, compared to the global picture of $80 \%$ deliveries during the same period [2]. In Ghana, about $74 \%$ of women had skilled deliveries, compared to $97 \%$ who received antenatal care (ANC) from skilled personnel in 2014 [3]. Available evidence suggests that various factors contribute to this gap in service utilization, one of which is client satisfaction with quality of service [4-6]. Client satisfaction is one aspect of adequate service provision, and its influence is currently being assessed in relation to reproductive and maternal healthcare in developing countries $[4,7,8]$. Client satisfaction can be indicative of the quality of the service provided and it is influenced by factors such as cost and staff members' attitude, among others [9-12]. The assessment of client satisfaction is vital in ensuring that clients receive quality care and that all services are client-oriented [9-12].

The Ghana Ensure Mothers and Babies Regular Access to Care (EMBRACE) implementation research project was launched in 2012 as part of efforts to improve the continuum of care in maternal, newborn, and child health in Ghana [13]. In the framework of the project, current practices on aspects of maternal, newborn, and child health indicators were examined [14]. In those studies, women's satisfaction with ANC services was suggested as a driving factor in their decision to deliver at a health facility with skilled health personnel [15]. While several studies have concentrated on general patient satisfaction and quality of health services in Ghana, the country does not have much information specifically on clients' satisfaction with delivery services, and most of the studies conducted in this area used quantitative designs [16]. In their systematic review of qualitative factors and barriers to facility-based delivery, however, Bohren and colleagues identified the need for quantitative findings to be explored in more depth through qualitative approaches [17].

As part of the EMBRACE evaluation to support the work done on satisfaction with delivery services in Ghana and sub-Saharan Africa, we used mixed methods to examine women's overall satisfaction with delivery services at health facilities in rural Ghana and identified the perceived factors that affected satisfaction with current services.

\section{Results}

Women's characteristics

Table 1 highlights the characteristics of 1130 participants who delivered in a health facility; $94 \%$ of participants were
Table 1 Women's socio-demographic characteristics

\begin{tabular}{|c|c|c|}
\hline Characteristics & $N=1130$ & $\%$ \\
\hline \multicolumn{3}{|c|}{ Background characteristics of all participants } \\
\hline \multicolumn{3}{|l|}{ Age (years) } \\
\hline$<20$ & 99 & 8.8 \\
\hline $20-29$ & 570 & 50.4 \\
\hline $30-39$ & 377 & 33.4 \\
\hline$\geq 40$ & 76 & 6.7 \\
\hline Unknown & 8 & 0.7 \\
\hline \multicolumn{3}{|l|}{ Education level } \\
\hline None & 386 & 34.2 \\
\hline Primary & 253 & 22.4 \\
\hline Middle/junior high school & 355 & 31.4 \\
\hline Secondary & 103 & 9.1 \\
\hline Tertiary and above & 33 & 2.9 \\
\hline \multicolumn{3}{|l|}{ Marital status } \\
\hline Married & 718 & 63.5 \\
\hline Cohabiting & 272 & 24.1 \\
\hline Divorced & 37 & 3.3 \\
\hline Never married & 103 & 9.1 \\
\hline \multicolumn{3}{|l|}{ Religion } \\
\hline Christian & 598 & 53.0 \\
\hline Islamic & 132 & 11.7 \\
\hline Traditional & 285 & 25.2 \\
\hline Other & 58 & 5.1 \\
\hline Missing & 57 & 5.0 \\
\hline \multicolumn{3}{|l|}{ Socio-economic characteristics } \\
\hline \multicolumn{3}{|l|}{ Wealth quintile } \\
\hline Least & 227 & 20.1 \\
\hline Less & 233 & 20.5 \\
\hline Wealthy & 221 & 19.7 \\
\hline Wealthier & 223 & 19.8 \\
\hline Wealthiest & 226 & 20.0 \\
\hline \multicolumn{3}{|c|}{ Valid health insurance card possession } \\
\hline Yes & 588 & 52.0 \\
\hline No & 542 & 48.0 \\
\hline \multicolumn{3}{|l|}{ Antenatal history } \\
\hline \multicolumn{3}{|l|}{ Timing of pregnancy } \\
\hline Got pregnant at the right time & 676 & 59.8 \\
\hline Wanted to get pregnant later & 353 & 31.3 \\
\hline Did not want to get pregnant & 10 & 8.9 \\
\hline \multicolumn{3}{|l|}{ Parity } \\
\hline 1 & 319 & 28.2 \\
\hline $2-3$ & 475 & 42.1 \\
\hline $4-5$ & 224 & 19.8 \\
\hline$>5$ & 112 & 9.9 \\
\hline
\end{tabular}


Table 1 Women's socio-demographic characteristics (Continued)

\begin{tabular}{lll}
\hline Characteristics & $N=1130$ & $\%$ \\
\hline Background characteristics of FGD participants & $N=136$ & $\%$ \\
Age (years) & & \\
$<20$ & 16 & 11.8 \\
$20-29$ & 58 & 42.6 \\
$30-39$ & 50 & 36.8 \\
$\geq 40$ & 12 & 8.8 \\
Education level & & \\
None & 49 & 36.0 \\
Primary & 35 & 25.7 \\
Middle/junior high school & 41 & 30.2 \\
Secondary & 9 & 6.6 \\
Tertiary and above & 2 & 1.5 \\
Marital status & & \\
Married & & 66.1 \\
Cohabiting & 90 & 22.8 \\
Divorced & 31 & 5.2 \\
Widowed & 7 & 0.7 \\
Never Married & 13.2 \\
Religion & 33 & 5.2 \\
Christian & 71 & \\
Islamic & 7 & 5.0 \\
Traditional & & \\
Other & 71 & \\
\hline
\end{tabular}

satisfied with overall care received during facility delivery. Their mean age was 29.0 (SD 9.0) years.

\section{Determinants of women's satisfaction with overall health facility delivery services}

In the univariate analysis, two independent variables were associated with overall satisfaction with health facility-based delivery services: education level and timing of pregnancy. In the multiple logistic regression analysis, education level was significantly associated with overall satisfaction with delivery services. Women with middle level/junior high school education [adjusted odds ratio $(\mathrm{AOR})=0.50,95 \%$ confidence interval $(\mathrm{CI})=(0.26-$ 0.98)] were less likely to be satisfied with overall delivery services compared to women with no education (Table 2)

\section{Qualitative study findings}

The background characteristics of the focus group discussions (FGD) respondents are described in Table 1. Two main themes emerged from the FGDs: satisfaction and dissatisfaction with delivery services. These themes were made up of sub-themes with greater details provided below (Table 3 ).

\section{Dissatisfaction with health facility delivery services}

Long wait time Some women stated that they were not satisfied with their delivery at the health facilities because of the long wait time. Two women explained their dissatisfaction as follows:

“... When we got there, there was nobody around. After settling down, we went to call them [health worker]; but, they did not come. We waited for a very long time" (19-year-old woman, Dodowa).

“... When I was going to give birth, they sent me to a health center and I waited for a long time. It was not until the nurses who give the folders realized that I was suffering; so, they looked for a car and sent me back to Navrongo to deliver" (28-year-old woman, Navrongo).

Negative attitude of health workers Most women were not satisfied with the services received from health workers during delivery, especially the attitude of the health workers during the labor. This was explained by two women as follows:

"When I was in pain, instead of the nurses taking care of me, they talked to me harshly. They are also women; so, they should understand what you are going through. Instead, they do things that they are not supposed to do such as talking to you harshly" (25-year-old woman, Dodowa).

" ... As for nurses when you go to them, they are supposed to be patient. However, I experienced problems with my pregnancy and I expected them to be patient with me; but, they were not. It was also my first pregnancy, and, instead of them to be patient and tell me what to do, they were shouting. Meanwhile, helping women to deliver is part of their work" (22year-old woman, Navrongo).

Unconventional demands from health workers One woman explained her dissatisfaction due to unconventional demands from health workers:

"When I was in labor and got to the hospital, they (health workers) asked me to go and jump and do some exercise. The little strength I had, they told me to do all sort of things and when I became weak and 
Table 2 Determinants of women's overall satisfaction with health facility delivery services

\begin{tabular}{|c|c|c|c|c|c|c|}
\hline Characteristics & Crude OR & $P$ value & $95 \% \mathrm{Cl}$ & Adjusted OR & $P$ value & $95 \% \mathrm{Cl}$ \\
\hline \multicolumn{7}{|l|}{ Education } \\
\hline None & Ref & & & Ref & & \\
\hline Primary & 0.91 & 0.76 & $0.49-1.69$ & 0.87 & 0.65 & $0.47-1.61$ \\
\hline Middle/junior high & 0.48 & $0.02^{*}$ & $0.25-0.91$ & 0.50 & $0.04^{*}$ & $0.26-0.98$ \\
\hline Secondary & 0.52 & 0.29 & $0.16-1.75$ & 0.55 & 0.35 & $0.16-1.91$ \\
\hline Tertiary and above & 0.34 & $0.04^{*}$ & $0.12-0.94$ & 0.38 & 0.06 & $0.14-1.04$ \\
\hline \multicolumn{7}{|l|}{ Timing of pregnancy } \\
\hline Satisfied with timing & Ref & & & Ref & & \\
\hline Wanted to get pregnant later & 2.02 & $0.04^{*}$ & $1.02-3.99$ & 1.92 & 0.06 & $0.98-3.76$ \\
\hline Did not want to get pregnant & 0.82 & 0.65 & $0.35-1.92$ & 0.70 & 0.42 & $0.30-1.65$ \\
\hline \multicolumn{7}{|c|}{ Complications during most recent delivery } \\
\hline Yes & Ref & & & Ref & & \\
\hline No & 1.57 & 0.10 & $0.92-2.67$ & 1.54 & 0.11 & $0.91-2.60$ \\
\hline
\end{tabular}

unable to give birth, they yelled at me and had me transferred. These are problems that affects us, and a lot of people prefer to give birth at home" (30-yearold woman, Dodowa).

Unavailability of health workers at facility Some women stated that health workers were not available at the facility during their time of delivery:

"... When we got to the facility, the woman who was to help me deliver was not there" (27-year-old woman, Navrongo).

Inconsistent treatment by health workers Some women stated that they were not satisfied with the inconsistent treatment received by different staff members during delivery. Asked to explain further, one participant summarized it as follows:

"... Some are always patient with us; but, others, they are not at all. What she is supposed to do to make everybody happy, she won't at all. She shouts at you like a child. They are not all the same...When I came to the facility to deliver, some were good to me, and some were not" (24-year-old woman, Dodowa).

\section{Satisfaction with health facility delivery services Satisfaction with health workers}

While most women were not satisfied with health workers, some women were completely satisfied with the health workers. They described them as people who gave respect, showed empathy, and provided good treatment during delivery. One woman had this to say regarding this:

“... They (health workers) really respect and treat you well when you go to give birth too. They know how to pamper you till you deliver and after delivery too they continue. The way they dress up your baby and also treat the mothers are very good. They even educated me on how to take care of myself before I went home" (30-year-old woman, Navrongo).

\section{Encouragement from health workers}

Aside from being satisfied with the treatment received during delivery, these women spoke highly of the health workers who attended to them. They were particularly grateful for the encouragement they received from health workers. One woman explained further:

"If your time is due for delivery, the nurses here motivate you and tell you to get courage to deliver safely. They even go ahead to give time of delivery.

Table 3 Themes and sub-themes identified in focus group discussions

\begin{tabular}{ll}
\hline Themes & Sub-themes \\
\hline Dissatisfaction & Long wait time \\
& Negative attitude of health workers \\
& Unconventional demands from health workers \\
& Low availability of health workers \\
& Inconsistent treatment by health workers \\
& Good treatment from health workers \\
Satisfaction & Encouragement from health workers
\end{tabular}


Unlike other places, during delivery, they don't shout at you" (32-year-old woman, Kintampo).

\section{Discussion}

Nearly all women who delivered were satisfied with the overall care they received during delivery at health facilities, according to the quantitative findings of the present study. The qualitative findings provide in-depth information on the various aspects of delivery services they were satisfied or dissatisfied with.

The quantitative results showed a relationship between education and satisfaction with delivery services, which both supports and contrasts prior literature. Montasser and colleagues from their study conducted in Egypt found no relationship between education level and satisfaction with delivery services [7]. Colombara and colleagues, on the other hand, from their study conducted in Central America noted that women with at least a primary education or higher were less likely to be satisfied with delivery services than those with no education [18]. This could be because these women expect to be given preferential treatment, which may also be the case in the present study.

The univariate logistic regression model used in our analysis showed that women were also satisfied or dissatisfied based on the timing of their pregnancy. Although this was not statistically significant in the multiple logistic regression model, it is consistent with other available publications on women's satisfaction with delivery services. Women who have unintended or unwanted pregnancies are less likely to be satisfied with delivery services $[4,19,20]$. This is attributed to the fact that these women are generally not happy and are worried about bringing up their newborn. These women may also experience other issues such as depression, lack of family support, or domestic abuse due to the fact that the pregnancy was unwanted [21].

The qualitative findings showed that that women's dissatisfaction with facility delivery services was influenced primarily by the behavior of health workers. This finding supports related work on satisfaction with quality of health services conducted in Ghana and other subSaharan countries. The poor attitudes of health workers in Ghana remain a major challenge as highlighted by Asamani and colleagues [22]. Recent reports by SEND-Ghana as well as Duku and colleagues on healthcare quality show that the bad attitude of health workers is often aimed particularly toward clients under the National Health Insurance Scheme (NHIS) [23, 24]. Ghanaian women who deliver at a health facility are not supposed to pay for the services provided as they are registered under NHIS [25]. The scheme was introduced in 2003 with the primary aim of ensuring that all registered residents have access to basic health services $[26,27]$. Free maternal healthcare was introduced under the NHIS in 2008 after an initial maternal exemption fee policy in 2005 and encourages women to access maternal health services such as ANC and delivery services at no cost to them [28-30]. There is growing evidence, however, that the NHIS is not always working as effectively as it should, resulting in nonavailability of some drugs at health facilities [31, 32]. In addition, even though the NHIS has improved access to health care, health workers have been accused of giving better services to patients who are able to pay for their drugs themselves, as compared to those who rely solely on the NHIS for payment [23].

Regarding workers' attitudes, some women revealed in the FGDs that, when health workers had shown respect and empathy toward them, it contributed immensely to their satisfaction with delivery services. This is consistent with the findings of earlier studies. Empathy from health workers has been shown to be a major contributor to satisfaction with delivery services among women who deliver in these health facilities [33,34], and in a study on satisfaction conducted by Bazant and colleagues among Kenyans, empathy from service providers such as health workers had a positive impact on patients' satisfaction [20]. Hodnett and colleagues conducted a systematic review of randomized controlled trials and found that women who experience complications during pregnancy value empathy from health workers and are therefore more likely to be satisfied with the delivery $[35,36]$. They also showed that women who have continuous support during delivery have a shorter labor period and are less likely to be dissatisfied with delivery services $[35,36]$.

Finally, our study highlighted the important role played by health workers in determining women's satisfaction with facility delivery services, which has a number of policy implications. Although not conclusive, our findings potentially support the need for a change in health workers' attitudes toward women during delivery. This is in line with the findings and recommendations by Asamani et al. in their study on poor attitudes of health workers, where they identified the need for sensitivity training for health workers, particularly when they assist patients during delivery [28]. This study also found that the Ghana Health Service (GHS) code of ethics as well as the code of conduct and disciplinary procedures were not being enforced in the health system [22]. These codes outline disciplinary measures for poor attitude of staff toward clients [37, 38]. More stringent measures are needed to enforce these codes, such as occasional monitoring and supervision by heads of health facilities to correct and maintain staff behavior. Official channels should be made available at the health facilities for clients to express such grievances. At the same time, clients should also be empowered to report 
such incidents of problematic behavior to prevent them from reoccurring.

There might be a need to increase the number of health professionals, especially midwives, at health facilities as the ratio of midwives to patients is quite low (nine midwives per 10,000 patients) [39]. The World Health Organization (WHO) recommends a ratio of at least 40 nursing and midwifery personnel per 10,000 [40]. Even though Ghana in 2016 had a nursing and midwifery personnel ratio of 33.7 per 10,000, nurses contributed a greater percent (over 90\%) compared with midwives [40]. Ghana's nursing and midwifery ratio was also lower than that of other neighboring SSA countries such as Cote D'Ivoire $(81.1$ per 10,000$)$ and Liberia $(67.1$ per 10,000$)$ within that period [40]. Task-strengthening of lower-level staff, such as community health officers/nurses (CHOs/ $\mathrm{CHNs}$ ) at CHPS, enabling them to aid with deliveries may help in resolving this challenge [41]. Task-sharing has been used previously in Ghana among CHOs in family planning to improve uptake of implants and may reduce staff members' workloads while improving working conditions, thus improving staff morale and subsequently fostering greater delivery satisfaction among women [42].

\section{Limitations and strengths}

This study had some limitations. First, overall satisfaction relied on women's reports, which could have introduced social desirability bias, as compared to other questions such as those on education, which were verified using the NHIS cards among others. Second, the primary focus of the quantitative survey was women's overall satisfaction, and this was binary. This meant that we could not gain a more granular understanding of the concept of quality service. However, the detailed, qualitative aspects of our study contribute to strengthening it. The mixed methods approach allowed for the use of qualitative interviews to explore the quantitative findings, thus providing a more complete understanding of satisfaction with delivery services in the study area. This was also a population-based survey in three different locations in Ghana, which comprised a representative sample of women from the lower, middle, and upper parts of the country who delivered at health facilities. Further, the exploratory aspect (i.e., FGDs) provided a very detailed perspective on why some women from the three study areas were satisfied or dissatisfied with delivery services at the health facilities.

\section{Conclusion}

Although nearly all women were satisfied with the overall service they received at health facilities during delivery, many were not satisfied with the long wait time or the attitudes of the health workers. Consequently, we recommend that these aspects of service delivery be tackled to improve women's satisfaction with delivery service and, subsequently, quality of care for maternal and child health.

\section{Methods \\ Study design}

This cross-sectional, mixed methods study was conducted in 2013 using an explanatory sequential design, which allowed for further investigations into the main quantitative finding using qualitative techniques [43].

\section{Study area}

The EMBRACE study was a collaborative effort between the Ghana Health Service (GHS), the University of Tokyo, and the Japan International Cooperation Agency Institute [13, 44]. The GHS has three health research centers (HRC): Kintampo, Dodowa, and Navrongo. They are located within the three main geographical zones of Ghana, where well-established health and demographic surveillance systems (HDSSs) collect population-based longitudinal data $[15,45]$. The Dodowa HRC is located within the Shai-Osu Doku and Ningo-Prampram districts of the Greater Accra region, comprising about 20 health facilities [14, 15]. The Kintampo HRC is in the middle part of Ghana within the Kintampo North Municipality and Kintampo South district in the Brong Ahafo region [46]. In this area, over 40 health facilities provide health services to a predominantly rural population [14, 15, 46]. The Navrongo HRC is in the Kassena-Nankana East and West districts of the Upper East region [47]. The center is renowned for the introduction of the community-based health planning and services concept and has over 50 health facilities [14, 42, 47].

\section{Sampling procedures and data collection}

Women $(N=1500)$ who had delivered in the preceding 2 years were interviewed using a structured questionnaire for the quantitative aspect of this study. Two-stage random sampling was used to recruit 500 women for each HDSS site [44]. Depending on the HDSS site, the primary sampling unit (PSU) was either the sub-district or the community-based health planning and services (CHPS) zone. The CHPS zones/sub-districts are regarded as the lowest health administration units in Ghana. The study areas contained 22 PSUs; women were randomly selected from each CHPS zone/sub-district using probability proportional to size. Women who delivered live or still births within the past 2 years and were resident in the selected areas from January 2011 to April 2013 were included. These women were then traced to their residence with the aid of the HDSS. The HDSS database provided the district, sub-district, community, and resident number (compound number) of participants. All women who provided written consent to be in the study were then interviewed by trained field workers. Field workers at each of the sites 
completed 2 days training concerning the questionnaire and other technical aspects of the study.

For the qualitative component, 15 (five per site) focus group discussions (FGDs) were conducted among 136 women who took part in the quantitative survey. For each HDSS site, five communities, which had been included in the quantitative survey, were purposively selected for the interviews. Between eight and 12 women who took part in the quantitative survey were then purposively selected from each of the five communities by the study team. These women were then contacted by the data collectors and a date was scheduled for the FGD. Women who were contacted and were willing to take part in the FGD were interviewed. The interviews were conducted by trained researchers from the three HDSS sites using an interview guide that was developed and pre-tested prior to data collection. These researchers also completed 2 days of intensive training in their respective sites. For each FGD conducted, one researcher served as the moderator and the other as a note taker. The duration of each FGD was 45 to $60 \mathrm{~min}$.

\section{Data collection tools and variables}

A structured questionnaire developed by the Ghana EMBRACE team was used for quantitative data collection. Key maternal neonatal and child health practices from pregnancy to delivery and postnatal care were the main focus of the EMBRACE study and questions on these indicators were incorporated. During questionnaire development, per prior literature, the team incorporated a question about satisfaction with delivery services. Since this was a mixed methods approach with a qualitative dimension, the team focused on women's overall satisfaction with health facilitybased delivery services. This was obtained using a binary question (with a yes/no answer) as used by the Ghana Demographic Health Survey for its population-based surveys [16]. The main question was framed as follows: "Taking into consideration the cleanliness of the health facility you visited during delivery, the waiting time, and the treatment received from staff amongst others, were you satisfied with the services received during your most recent pregnancy at the health facility?". "That is to say, were you satisfied with your delivery services?" The questionnaire was initially tested among selected participants outside the study area. The questionnaire also included questions on the respondents' background characteristics such as women's age, education level, marital status, religion, timing of pregnancy, number of pregnancies, complications during delivery, and place of delivery. Socio-economic status included possession of a valid health insurance card and wealth quintile. The main dependent variable was women's overall satisfaction with health facility-based delivery services. Wealth quintile was measured using assets and was generated based on the methods used by demographic and health surveys [15].

An FGD guide complemented the survey questionnaire. The interviews were recorded using a digital audio recorder. In addition to other questions, the main question asked in the FGD was, "What accounted for your overall satisfaction or otherwise with the health facility delivery services received during your most recent pregnancy at the health facility?"

\section{Data analyses}

Women's background characteristics were described and reported as proportions. A univariate logistic regression analysis was conducted to determine the relationship between women's overall satisfaction with facility delivery services and each independent variable. Further analyses were completed using multiple logistic regression analyses. Out of 1500 data entries, we included 1130 in the analysis, with some excluded because of missing key background information $(n=3)$, duplicate maternal information in the case of twins $(n=6)$, or miscarriage $(n=1)[42,44]$. We also excluded women who did not deliver in a health facility $(n=360)$ [15].

The following variables identified by the EMBRACE team from literature were used for the univariate logistic regression model: education, timing of pregnancy, age, marital status, location, possession of a valid insurance card, number of children, satisfaction with ANC, place of delivery, who assisted with the delivery, complications during delivery, and maternal check-up after delivery [4, $7,16,20,48,49]$. For the multiple logistic regression model, variables from the univariate model that were found to have significant association with women's overall satisfaction at $p \leq 0.20$ were included. These were education, timing of pregnancy, and complications during the last delivery. The probable variables with multicollinearity were thus excluded from the analyses and no collinearity was observed among the variables used in the multiple regression model. Statistical significance was set at $p<0.05$. The clustering observed as a result of the study design was accounted for using generalized estimated equations (GEE). GEE uses robust estimation of standard errors which caters for clustering. All analyses were conducted using Stata version 12 (Stata Corporation, College Station, TX). The reference group options for the logistic regression were not specified but chosen by default in Stata.

For the qualitative component, the running notes from the FGDs were expanded. The audio recordings were also transcribed and read several times to clean the data. Translation of interviews that were conducted in the local language was done during the transcription. The information collected was listed in Microsoft Word 2012. The transcription data were coded according to 
themes, which were categorized manually to reflect themes. Although predefined themes were formed from the interview guide prior to data collection, some evolved as data analyses progressed. The qualitative analysis focused primarily on perceived factors affecting satisfaction and dissatisfaction with facility delivery services based on participants' experiences.

\section{Abbreviations \\ ANC: Antenatal clinic; aOR: Adjusted odds ratio; CHN: Community health nurse; CHOs: Community health officers; CHPS: Community-based health planning and services; $\mathrm{Cl}$ : Confidence interval; cOR: Crude odds ratio; EMBRACE: Ensure Mothers and Babies Regular Access to Care; FGD: Focus group discussions; GEE: Generalized estimated equation; GHS: Ghana Health Service; HDSS: Health and demographic surveillance systems; HRC: Health research centres; IEC: Institutional ethics committee; IRB: Institutional review board; NHIS: National Health Insurance Scheme; PSU: Primary sampling unit; RDD: Research and development division; REC: Research ethics committee; SD: Standard deviation; SSA: Sub-Saharan Africa; WHO: World Health Organization}

\section{Acknowledgements}

We thank the Ministry of Health in Ghana and the Ministry of Foreign Affairs, Japan. We are also indebted to the Ghana Health Service and the District Health Management Teams of the Kintampo North, Kintampo South, Shai Osu-Doku, Ningo-Prampram, Kassena-Nankana East, and Kassena Nankana West. The Ghana EMBRACE Implementation project was conducted by the Government of the Republic of Ghana, Japan International Cooperation Agency (JICA) Human Development Department and JICA research institute. The views expressed in this manuscript are solely those of the authors and do not necessarily represent that of JICA human development department, JICA research institute, or Ghana Health Service. The Ghana EMBRACE Implementation Research project including the authors are as follows: Yoshiharu Yoneyama, Ebenezer Appiah-Denkyira, Masamine Jimba, Abraham Hodgson, Gloria Quansah Asare, Evelyn Korkor Ansah, Junko Yasuoka, Keiko Nanishi, Akira Shibanuma, Kimiyo Kikuchi, Sumiyo Okawa, Margaret Gyapong, Sheila Addei, Vida Kukula, Doris Sarpong, Clement Narh, Seth Owusu-Agyei, Kwaku Poku-Asante, Ernest Nettey, Charlotte Tawiah, Yeetey Enuameh, Kwame K. Adjei, Solomon Narh-Bana, Emmanuel Mahama, Francis Dzabeng, Abraham Rexford Oduro, John Williams, Cornelius Debpuur, Francis Yeji, Evelyn Sakeah, Peter Wontuo, Akiko Hagiwara, Sakiko Shiratori, Yusuke Kamiya, and Enoch Oti Agyekum.

\section{Funding}

This paper was funded by the Japan International Cooperation Agency (JICA) Human Development Department, and JICA Research Institute.

\section{Availability of data and materials}

The datasets used and/or analyzed in this study are available from the corresponding author upon reasonable request.

\section{Authors' contributions}

KKA, KK, SOA, YE, AK, EKA, YJ, KP, SO, MG, CT, ARO, ES, DS, GQA, AH, and MJ all contributed to the conceptualization of the research, study design, and revision of manuscript. KKA, KK, SOA, YE, and AK contributed to the formal analysis of the manuscript. KKA, KK, SOA, and YE contributed to the writing of manuscript. $A K, S O, C T, K P, Y J, A H$, and $M J$ contributed to the critical review and interpretation of the manuscript. All authors have read the manuscript and accept responsibility for any issues that may arise as a result of publishing this manuscript. All authors read and approved the final manuscript.

\section{Ethics approval and consent to participate}

Before implementing the study, ethical clearance was obtained from the Ethical Review Committee (ERC) of the research and development division (RDD) of the GHS; the research ethics committee (REC) of the University of Tokyo, Japan; the institutional review board (IRB) of the Dodowa HRC; the institutional ethics committee (IEC) of the Kintampo HRC; and the Institutional Review Board of the Navrongo HRC. Written informed consent was sought from all participating women, who were informed about the study purpose, its risks and benefits, privacy, confidentiality, conflicts of interest, and that participation was voluntary. Women aged below 18 years provided assent and their guardians provided consent. Strict confidentiality was enforced throughout.

\section{Consent for publication}

Not applicable.

\section{Competing interests}

The authors declare that they have no competing interests.

\section{Publisher's Note}

Springer Nature remains neutral with regard to jurisdictional claims in published maps and institutional affiliations.

\section{Author details}

${ }^{1}$ Kintampo Health Research Centre, Kintampo, Brong-Ahafo, Ghana. ${ }^{2}$ Institute of Decision Science for a Sustainable Society, Kyushu University, Fukuoka, Japan. ${ }^{3}$ University of Health and Allied Science, Ho, Ghana. ${ }^{4}$ Kwame Nkrumah University of Science and Technology, Kumasi, Ghana. ${ }^{5}$ Department of Community and Global Health, Graduate School of Medicine, The University of Tokyo, 7-3-1, Hongo, Bunkyo-ku, Tokyo 113-0033, Japan. ${ }^{6}$ Research and Education Center for Prevention of Global Infectious Diseases of Animals, Tokyo University of Agriculture and Technology, Tokyo, Japan. ${ }^{7}$ Navrongo Health Research Centre, Navrongo, Ghana. ${ }^{8}$ Dodowa Health Research Centre, Dodowa, Greater Accra, Ghana. ${ }^{9}$ Office of International Academic Affairs, Graduate School of Medicine and Faculty of Medicine, The University of Tokyo, Tokyo, Japan. ${ }^{10}$ Ghana Health Service, Accra, Ghana. ${ }^{11}$ Research and Development Division, Ghana Health Service, Accra, Ghana.

Received: 15 January 2019 Accepted: 26 June 2019

Published online: 05 July 2019

\section{References}

1. United Nations. The millennium development goals report. 2014. http:// www.un.org/millenniumgoals/2014\%20MDG\%20report/ MDG\%202014\%20English\%20web.pdf. Accessed 16 Nov 2018.

2. World Health Organization. Global Health Observatory data: skilled attendants at birth. https://www.who.int/gho/maternal_health/skilled_care/ skilled_birth_attendance_text/en/. Accessed 26 Mar 2019.

3. Ghana Statistical Service, Ghana Health Service, ICF International. Ghana demographic and health survey 2014. 2015. https://dhsprogram.com/ publications/publication-FR307-DHS-Final-Reports.cfm. Accessed 16 Nov 2018

4. Andaleeb SS, Siddiqui N, Khandakar S. Patient satisfaction with health services in Bangladesh. Health Policy Plan. 2007;22(4):263-73.

5. Kyei-Nimakoh M, Carolan-Olah M, McCann TV. Access barriers to obstetric care at health facilities in sub-Saharan Africa-a systematic review. Syst Rev. 2017:6(1):110.

6. Moyer C, Mustafa A. Drivers and deterrents of facility delivery in sub-Saharan Africa: a systematic review. Reprod Health. 2013;10(1):40.

7. Montasser NAE-H, Helal RM, Megahed WM, Amin SK, Saad AM, Ibrahim TR, et al. Egyptian women's satisfaction and perception of antenatal care. Int J Trop Dis Health. 2012;2(2):145-56.

8. Jallow IK, Chou YJ, Liu TL, Huang N. Women's perception of antenatal care services in public and private clinics in the Gambia. Int J Qual Health Care. 2012:24(6):595-600

9. Gitobu C, Gichangi P, Mwanda W. Satisfaction with delivery services offered under the free maternal healthcare policy in Kenyan public health facilities. J Environ Public Health. 2018;2018(4):1-9.

10. Tesfaye R, Worku A, Godana W, Lindtjorn B. Client satisfaction with delivery care service and associated factors in the public health facilities of Gamo Gofa zone, Southwest Ethiopia: in a resource limited setting. Obstet Gynecol Int. 2016:57980698.

11. Wung BA, Peter NF, Atashili J. Clients' satisfaction with HIV treatment services in Bamenda, Cameroon: a cross-sectional study. BMC Health Serv Res. 2016;16:280. https://doi.org/10.1186/s12913-016-1512-5.

12. Bitew K, Ayichiluhm M, Yimam K. Maternal satisfaction on delivery service and its associated factors among mothers who gave birth in public health facilities of Debre Markos town, Northwest Ethiopia. Biomed Res Int 2015. 2015:460767. 
13. Kikuchi K, Ansah E, Okawa S, Shibanuma A, Hodgson A, Jimba M, et al. Ghana's Ensure Mothers and Babies Regular Access to Care (EMBRACE) program: study protocol for a cluster randomized controlled trial. Trials. 2015;16:22.

14. Yeji F, Shibanuma A, Oduro A, Debpuur C, Kikuchi K, Owusu-Agei S, et al. Continuum of care in a maternal, newborn and child health program in Ghana: low completion rate and multiple obstacle factors. PLoS One. 2015; 10(12):e0142849.

15. Enuameh Y, Okawa S, Asante KP, Kikuchi K, Jimba M, Owusu-Agyei S, et al Factors influencing health facility delivery in predominantly rural communities across the three ecological zones in Ghana: a cross-sectional study. PLoS One. 2016;11(3):e0152235l.

16. Avortri GS, Beke A, Abekah-Nkrumah G. Predictors of satisfaction with child birth services in public hospitals in Ghana. Int J Health Care Qual Assur. 2011;24(3):223-37.

17. Bohren MA, Hunter EC, Munthe-Kaas HM, Souza JP, Vogel JP, Gülmezoglu AM. Facilitators and barriers to facility-based delivery in low-and middle-income countries: a qualitative evidence synthesis. Reprod Health. 2014;11(1):71.

18. Colombara DV, Hernández B, Schaefer A, Zyznieuski N, Bryant MF, Desai SS, et al. Institutional delivery and satisfaction among indigenous and poor women in Guatemala, Mexico, and Panama. PLoS One. 2016;11(4): e015438819.

19. Abera M, Gebremariam A, Belachew T. Predictors of safe delivery service utilization in Arsi zone, South-East Ethiopia. Ethiopian J Health Sci. 2011; 21(3):95-106.

20. Bazant ES, Koenig MA. Women's satisfaction with delivery care in Nairobi's informal settlements. Int J Qual Health Care. 2009:21(2):79-86.

21. Umurungi SY. Determinants of the utilisation of delivery services by pregnant women in Rwanda [dissertation]. 2011. https://core.ac.uk/ download/pdf/39668024.pdf. Accessed 16 Nov 2018.

22. Asamani L, Agyemang BC, Afful J, Asumeng M. Work attitude of Ghanaian nurses for quality health care service delivery: application of individual and organizational centered (IOC) interventions. Int J Res. 2017;7(1):37-46.

23. Duku SKO, Nketiah-Amponsah E, Janssens W, Pradhan M. Perceptions of healthcare quality in Ghana: does health insurance status matter? PLoS One. 2018;13(1):e0190911.

24. GBC Ghana. SEND Ghana survey reveals "poor attitude" of nurses towards patients. https://wwwgbcghanacom/111405521 2017. Accessed 25 Mar 2019.

25. National Health Insurance Authority. Annual report, 2009. 2010. http://www. nhis.gov.gh/files/1(1).pdf. Accessed 16 Nov 2018.

26. Sarpong N, Loag W, Fobil J, Meyer CG, Adu-Sarkodie Y, May J, et al. National health insurance coverage and socio- economic status in a rural district of Ghana. Tropical Med Int Health. 2010;15(2):191-7.

27. Jehu-Appiah C, Aryeetey G, Agyepong I, Spaan E, Baltussen R. Household perceptions and their implications for enrolment in the national health insurance scheme in Ghana. Health Policy Plan. 2012;27(3):222-33.

28. Jehu-Appiah C, Aryeetey G, Spaan E, de Hoop T, Agyepong I, Baltussen R. Equity aspects of the national health insurance scheme in Ghana: who is enrolling, who is not and why? Soc Sci Med. 2011;72(2):157-65.

29. Singh K, Osei-Akoto I, Otchere F, Sodzi-Tettey S, Barrington C, Huang C, et al. Ghana's national health insurance scheme and maternal and child health: a mixed methods study. BMC Health Serv Res. 2015;15(1):108.

30. Gudu W, Addo B. Factors associated with utilization of skilled service delivery among women in rural northern Ghana: a cross sectional study. BMC Pregnancy Childbirth. 2017;17(1):159.

31. Blanchet NJ, Fink G, Osei-Akoto I. The effect of Ghana's national health insurance scheme on health care utilisation. Ghana Med J. 2012;46(2):76-84.

32. Asante F, Arhinful D, Fenny A, Kusi A. Who is excluded in Ghana's national health insurance scheme and why: a social, political, economic and cultural (SPEC) analysis. 2014. http://dspace.itg.be/bitstream/handle/10390/8131/ 2014wegn0012.pdf?sequence=1. Accessed 16 Nov 2018.

33. DiMatteo MR, Hays RD, Prince LM. Relationship of physician' nonverbal communication skill to patient satisfaction, appointment noncompliance, and physician workload. Health Psychol. 1986;5(6):581-94.

34. Birhanu Z, Assefa T, Woldie M, Morankar S. Determinants of satisfaction with health care provider interactions at health centres in Central Ethiopia: a cross sectional study. BMC Health Serv Res. 2010;10(1):78.

35. Hodnett ED, Gates S, Hofmeyr GJ, Sakala C, Weston J. Continuous support for women during childbirth. Cochrane Database Syst Rev. 2011;2(2): CD003766.
36. Hodnett ED, Fredericks S, Weston J. Support during pregnancy for women at increased risk of low birthweight babies. Cochrane Database Syst Rev. 2010;6(6):CD000198

37. Ghana Health Service. Code of Conduct and Disciplinary Procedures. 2003. http://www.ghanahealthservice.org/ghs-item-details.php?cid=5\&scid= 52\&iid=87. Accessed 25 Mar 2019

38. Ghana Health Service. Code of Ethics. http://www.ghanahealthservice.org/ ghs-subcategory.php?cid=2\&scid=45. Accessed 25 Mar 2019.

39. World Health Organization. World Health Statistics. 2015. https://www.who. int/gho/publications/world_health_statistics/2015/en/. Accessed 1 Apr 2019.

40. World Health Organization. Density of Nursing and Midwifery Personnel. https://www.who.int/gho/health_workforce/nursing_midwifery_density/en/ Accessed 12 Jun 2019.

41. Population Council. Increasing access to family planning in Ghana through policy change: task-sharing to enable auxiliary nurses to provide contraceptive implant services. 2014. https://www.popcouncil.org/uploads/ pdfs/2014RH_GhanaTaskSharingPolicyBrief.pdf . Accessed 1 Apr 2019.

42. Evelyn S, Okawa S, Oduro AR, Akira S, Ansah E, Kikuchi K, et al. Determinants of attending antenatal care at least four times in rural Ghana: analysis of a cross-sectional survey. Glob Health Action. 2017;10(1):1291879.

43. Creswell JW. Steps in conducting a scholarly mixed methods study. DBER Speaker Series. 2013 [cited 2018 Nov 12];48 [about 54 p]. http:// digitalcommons.unl.edu/dberspeakers/48/?utm_source=digitalcommons.unl. edu\%2Fdberspeakers\%2F48\&utm_medium=PDF\&utm_campaign= PDFCoverPages. Accessed 16 Nov 2018.

44. Okawa S, Ansah EK, Nanishi K, Enuameh Y, Shibanuma A, Kikuchi K, et al. High incidence of neonatal danger signs and its implications for postnatal care in Ghana: a cross-sectional study. PLoS One. 2015;10(6):e0130712.

45. Sankoh O, Byass P. The INDEPTH network: filling vital gaps in global epidemiology. Int J Epidemiol. 2012;41(3):579-88.

46. Owusu-Agyei S, Ernest A, Nettey O, Zandoh C, Sulemana A, Adda R, et al. Demographic patterns and trends in Central Ghana: baseline indicators from the Kintampo health and demographic surveillance system. Glob Health Action. 2012;5(1):19033.

47. Oduro AR, Wak G, Azongo D, Debpuur C, Wontuo P, Kondayire F, et al. Profile of the Navrongo health and demographic surveillance system. Int J Epidemiol. 2012:41(4):968-76.

48. Ghana Statistical Service, Ghana Health Service, ICF International. Ghana demographic and health survey 2008. 2009. https://www.dhsprogram.com/ pubs/pdf/FR221/FR221\%5B13Aug2012\%5D.pdf Accessed 16 Nov 2018.

49. Turkson P. Client satisfaction survey of healthcare delivery in rural Ghana using service quality measurement (SERVQUAL) approach. Ghana Soc Sci J. 2008;5\&6:217-35.

Ready to submit your research? Choose BMC and benefit from:

- fast, convenient online submission

- thorough peer review by experienced researchers in your field

- rapid publication on acceptance

- support for research data, including large and complex data types

- gold Open Access which fosters wider collaboration and increased citations

- maximum visibility for your research: over $100 \mathrm{M}$ website views per year

At $\mathrm{BMC}$, research is always in progress.

Learn more biomedcentral.com/submission 